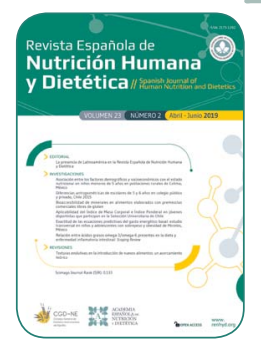

\title{
REVISIÓN
}

\section{Texturas evolutivas en la introducción de nuevos alimentos: un acercamiento teórico}

\author{
Olga Brunner-López ${ }^{a}$, María Jesús Fuentes-Martín ${ }^{a}, *$, Berta Ortigosa-Pezonaga ${ }^{a}$, \\ Ana María López-García ; Grupo de Especialización de Nutrición Pediátrica \\ de la Academia Española de Nutrición y Dietética
}

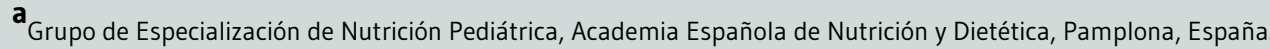

*nutpedia@academianutricion.org
}

Editor asignado: Eduard Baladia. Comité Editorial de la Revista Española de Nutrición Humana y Dietética. Pamplona, España.

Recibido el 8 de septiembre de 2017; aceptado el 21 de junio de 2019; publicado el 21 de junio de 2019.

\section{PALABRAS CLAVE}

\section{Fenómenos}

Fisiológicos

Nutricionales del

Lactante;

\section{Ciencias de la}

Nutrición del Niño;

Alimentos Infantiles;

Fenómenos

Fisiológicos Orales y del Sistema Digestivo;

Obstrucción de las

Vías Aéreas;

Desempeño

Psicomotor.
Texturas evolutivas en la introducción de nuevos alimentos: un acercamiento teórico

\section{RESUMEN}

En la actualidad, existe un debate sobre el mejor método a elegir para iniciar la alimentación del lactante. Los modelos analizados para llevar a cabo la alimentación son: la alimentación con textura modificada dirigida por los padres o cuidadores y la alimentación con textura mínimamente modificada y dirigida por el bebé como los métodos baby-led weaning (BLW) y baby lead introduction to solids (BLISS). Este documento, tiene como finalidad ayudar, desde el punto de vista teórico, en el debate sobre las posibles texturas a utilizar en cada momento, atendiendo a diferentes factores, como son: el desarrollo digestivo, el ritmo de dentición, la evolución de la masticación, las habilidades psicomotoras y la prevención de asfixia o atragantamiento. En el texto, se clasifican las texturas que se usan en todos los métodos, según los ítems que se han estudiado, para que posteriormente puedan ser usadas como una guía orientativa según edades en bebés sanos y con un crecimiento dentro de los percentiles. Teniendo como base la evidencia científica más actual encontrada y primando el principio de precaución, el acercamiento teórico al problema añade matices a tener en cuenta en la evaluación empírica. Se requieren más estudios y de mayor calidad para identificar diferencias en el impacto del uso de diferentes texturas y prácticas alimentarias. 
Evolutionary texture in new food introduction: a theoretical approach

\section{KEYWORDS}

Infant Nutritional Physiological Phenomena;

Child Nutrition

Sciences;

Infant Food;

Digestive

System and Oral

Physiological

Phenomena;

Airway Obstruction;

Psychomotor

Performance.

\section{ABSTRACT}

Nowadays, there is a debate about the best method to choose to start feeding the infant. The models analyzed to carry out the feeding are: the modified textured feeding directed by the parents or caregivers and the feeding with minimally modified texture directed by the baby such as the baby-led weaning (BLW) and baby lead introduction to solids (BLISS) methods. The purpose of this document is to help, from a theoretical point of view, in the debate on the possible textures to be used at any time, taking into account different factors, such as: digestive development, dentition rhythm, chewing evolution, psychomotor skills and prevention of suffocation or choking. In the text, the textures that are used in all the methods are classified, according to the items that have been studied, so that later they can be used as an orientation guide according to ages in healthy babies and with a growth within the percentiles. Based on the most current scientific evidence found and prioritizing the precautionary principle, the theoretical approach to the problem adds nuances to be taken into account in the empirical evaluation. More studies and higher quality are required to identify differences in the impact of the use of different textures and food practices.

\section{CITA}

Brunner-López O, Fuentes-Martín MJ, Ortigosa-Pezonaga B, López-García AM; Grupo de Especialización de Nutrición Pediátrica de la Academia Española de Nutrición y Dietética. Texturas evolutivas en la introducción de nuevos alimentos: un acercamiento teórico. Rev Esp Nutr Hum Diet. 2019; 23(2): 104-22. doi: 10.14306/ renhyd.23.2.459

\section{INTRODUCCIÓN}

El periodo de la alimentación complementaria, o beikost, es un periodo de adaptación a los nuevos alimentos de una forma progresiva y lenta. A través del cual, el bebé pasará de alimentarse únicamente de la leche materna a complementarla con otros alimentos sanos, naturales, mínimamente procesados y familiares, siguiendo su propio ritmo.

No hay una fecha exacta para iniciar la introducción de alimentos, pero sí que existe un rango de edad en el que nunca se debe iniciar; este rango indica que no antes de los 4 meses, ni posponerlo más tarde de los 7 meses. Esta diferencia tan amplia se debe a que el desarrollo de cada bebé es diferente, aunque en general, dentro de este rango, se podría decir que están preparados a nivel de maduración renal, inmunológica, gastrointestinal, neurológica y psicomotriz $z^{1,2,3}$. Es, además, alrededor de los 6 meses cuando las necesidades de crecimiento y desarrollo del bebé aumentan, siendo insuficientes algunos micronutrientes aportados a través de la leche como la vitamina D y el hierro 4,5 . A partir del 2003, la Organización Mundial de la Salud (OMS) cambió sus recomendaciones y marcó los 6 meses como fecha para iniciar el beikost (manteniendo la lactancia materna, al menos hasta los 2 años), y siendo la leche materna o de fórmula el alimento principal hasta el año, y el resto de los alimentos como complementarios para asegurar un aporte nutricional suficiente, reducir anemias, no comprometer el crecimiento y la salud a largo plazo, así como reducir el sobrepeso, ya que se sugiere que se fomenta si se hace una introducción temprana ( 4 meses) ${ }^{6}$.

La desnutrición en los dos primeros años de vida es causa de desnutrición crónica, pudiendo afectar a la talla final, al coeficiente intelectual e inclusive a la reproducción en edad adulta7. Dentro de los propósitos para el 2025 que marca la OMS, se encuentra reducir en un $40 \%$ el retraso en el crecimiento, conseguir que no aumente el sobrepeso y aumentar a un 50\% la lactancia materna mantenida como mínimo hasta los 6 meses, aunque lo ideal sería hasta los 2 años o más 8,9 . 
La lactancia materna, entre otros beneficios, podría ayudar al desarrollo de comportamientos alimentarios protectores contra la obesidad por medio del respeto de las sensaciones de hambre y saciedad ${ }^{10}$.

Para iniciar el beikost o diversificación de alimentos se pueden usar varios métodos:

- Tradicional: ofrece purés cocinados usando alimentos procesados especiales para bebés, junto con otros naturales. Modificando su textura a medida que el bebé va creciendo. En este modelo, son los padres los que guían la alimentación a partir de la cuchara.

- BLW y BLISS: ofrecen alimentos naturales y procesados, mezclados y manipulados para que puedan ser comidos con las manos, desde los inicios. Será el propio bebé quien guíe su propia alimentación ${ }^{11}$.

Todos ellos tienen pros y contras, por eso el uso de uno u otro está a debate actualmente. Las diferencias radican a nivel nutricional (por defecto o exceso tanto energético como de micronutrientes), por mayor o menor riesgo de atragantamiento, o por fomentar o dificultar conceptos como: el desarrollo de la autonomía, preferencias alimentarias saludables, alargar la lactancia materna, mejorar la relación emocional con la comida y la familia, regulación de la saciedad, problemas a la hora de comer, consecuencias antropométricas (sobrepeso o bajo peso), así como la aparición de posibles enfermedades a corto plazo $0^{6,12-17}$.

La controversia puede ser debida a que los métodos BLW y BLISS son muy nuevos y, aunque sugieren que fomentan el desarrollo de un comportamiento alimentario positivo, la mayoría de los estudios actuales a excepción de 2, son estudios observacionales con resultados autoinformados y con metodologías de poca calidad, con falta de datos, pocos participantes, sesgos potenciales, etc. y muy diferentes entre ellos, como para que se pueda comparar adecuadamente. Los resultados que ofrecen se tienen que interpretar con cuidado, sobre todo en temas como: riesgo de asfixia, deficiencia de hierro, energía y bajo peso, crecimiento y preferencias alimentarias de sabores dulces o salados. Actualmente aún hay muchos temas sin resolver y faltan estudios que relacionen los métodos que se han usado para realizar el beikost y su relación con las preferencias alimentarias en edades preescolares, enfermedades futuras y el microbioma intestinal. Así como estudios que indiquen cómo se debe aplicar cada método basándose en una evidencia científica. Todos estos aspectos hacen que hasta el momento, no haya un consenso de cuál es el mejor método, si realmente existe uno ideal o si la mejor opción podría ser una fusión con lo mejor de cada uno de ellos y que se lleve a cabo de una forma personalizada según la evolución de cada bebé6,17,18.
Esta controversia, así como la falta de consenso entre los profesionales sanitarios y de estudios sobre cómo hay que pasar de la teoría a la práctica, hace que los padres desconfíen de los profesionales sanitarios y que al final decidan seguir sus instintos y escojan el método que mejor se adapte a su hijo y familia, en función de una serie de factores como: crecimiento, sueño, felicidad, edad, familia, economía, cultura, publicidad, etiquetado de alimentos, etc. ${ }^{19}$. Hasta que la ciencia avance, nuestra intención es aportar información sobre el debate existente y hacer una revisión sobre los hitos del desarrollo más importantes del bebé, para poder clasificar las texturas que se usan en todos los métodos según las edades y que al mismo tiempo no fomenten el atragantamiento. La información recopilada servirá para que tanto los profesionales sanitarios como los padres, independientemente del método que se escoja, sean capaces de asesorar o cocinar las texturas que necesiten dentro de cada momento, dentro de alimentación sana, equilibrada, saludable, suficiente, satisfactoria, familiar y segura.

Objetivos: Se trata de hacer una puesta al día sobre cómo se puede adaptar la alimentación en el periodo de la introducción de nuevos alimentos según la evolución fisiológica, anatómica y de psicomotricidad del bebé, de una forma personalizada y siguiendo recomendaciones basadas en la evidencia científica, y ver si estos hitos del desarrollo pueden servir como indicativos en la elección de una u otra textura para iniciar el beikost.

Como objetivos más específicos, nos proponemos: hacer un resumen de las texturas que se usan en todos los métodos y que se han ido proponiendo en las diferentes guías internacionales y estudios científicos; encontrar qué texturas pueden resultar las más adecuadas por rango de edades, por hitos de desarrollo y que no propicien los atragantamientos; y revisar los distintos métodos de beikost y estudios que hablen de alimentos conflictivos para bebés, para ver si se relacionan con la asfixia y el atragantamiento.

\section{METODOLOGÍA}

Para elaborar el documento se parte de la revisión bibliográfica extraída de bases de datos como: PubMed, Practice-based Evidence in Nutrition (PEN), OMS, American Academy of Pediatrics (AAP), Asociación Española de Pediatría (AEP), European Food Safety Authority (EFSA) entre otras. Aplicando una serie de filtros y palabras clave en el colectivo de bebés sanos, nacidos a término y que se encuentren dentro de la tabla de percentiles. 
A partir de esta información recogida, el artículo se ha estructurado en una serie de resúmenes y tablas de elaboración propia en relación a la fisiología digestiva, ritmo de dentición, evolución de la masticación y habilidades psicomotoras, para elaborar posteriormente una tabla de texturas adecuadas a cada rango de edad.

\section{EVOLUCIÓN DIGESTIVA}

Al igual que otros órganos, el aparato digestivo está inmaduro en el momento del nacimiento y va madurando hasta los 3 años, edad que se equipara más a las características fisiológicas del aparato digestivo del adulto. A continuación, se reflejan algunos de los datos más significativos de la fisiología digestiva en este rango de edad.

\section{4-12 meses}

\section{Digestión de las grasas ${ }^{19-25}$}

El bebé obtiene un aporte calórico del 40-55\% proveniente de la grasa láctea, lo que supone consumir unos 4,6-6g de grasa láctea/kg peso/día.

Los aspectos digestivos a tener en cuenta para la digestión de las grasas serían los siguientes:

Lipasa lingual: se encuentra en niveles óptimos para hidrolizar en el estómago los triglicéridos de cadena corta y media. Se mantiene activa pese a la acidez estomacal.

Lipasa gástrica o Esterasa gástrica: niveles óptimos para hidrolizar los triglicéridos de cadena media y larga.

Lipasa pancreática: misma cantidad que en la edad adulta. Esta enzima es importante, porque las anteriores lipasas se inactivan en el duodeno.

Lipasas de la leche materna (lipoproteinlipasa y lipasa estimulada por ácidos biliares): estas enzimas se mantienen estables a pH de 3,5 y no son hidrolizadas por las enzimas proteolíticas intestinales, por lo que los lactantes podrán digerir mejor las grasas frente a los bebés alimentados con fórmula. Este beneficio se reduce del $90-95 \%$ al $70 \%$ si se consume leche materna congelada y calentada al baño maría a $<100^{\circ} \mathrm{C}$.

Sales biliares: tienen todavía menor capacidad para concentrarse en la vesícula que respecto a las de un adulto. Presenta un $50 \%$ las sales tauroconjugadas y un $5 \%$ las glicinoconjugadas. Su "pool" biliar es 50\% menor que el adulto, siendo la secreción y reabsorción de sales biliares intestinales y la captación hepática deficitaria. Será a los 8 meses cuando se dé la correcta reabsorción. Presenta una concentración duodenal de $1-2 \mathrm{mMol} / \mathrm{L}$ cuando se necesitan 2-5mMol/L para formar micelas y solubilizar correctamente las grasas, además de un pH 7-8. Entre los 2-7 meses se establece el modelo conjugado con la glicina. A pesar de todo esto, el lactante no presenta problemas relacionados con este déficit fisiológico de la secreción biliar.

Interacción calcio-grasas: la alta ingesta de calcio de los bebés interfiere en la absorción de las grasas, esto no pasará en bebés más grandes.

\section{Digestión de los hidratos de carbono $7,20,22,23,26,27$}

Se calcula que las necesidades de hidratos de carbono rondan entre los $10-14 \mathrm{~g} / \mathrm{kg}$ peso/día, lo que supone entre un 40-50\% del valor calórico total. Las lactasas intestinales serán las encargadas de digerir la lactosa que es el hidrato de carbono principal en la leche humana.

Los aspectos digestivos de los hidratos de carbono son los siguientes:

Absorción de monosacáridos: se absorben entre el 50-60\% ya desde el nacimiento.

Amilasa salival $\boldsymbol{\alpha}$-amilasa: deficitaria hasta los 6 meses, pero no impide que se toleren cantidades de $5,5-6 \mathrm{~g} / \mathrm{kg}$ peso/día de almidón al inicio, que se podrán incrementar progresivamente (siendo la tolerancia del 99\% del total de hidratos consumidos a los 12 meses). Los polímeros del arroz o maíz se hidrolizan mejor, por eso se recomienda iniciar la alimentación con cereales bajos en gluten como éstos. Para hacer su función necesita un $\mathrm{pH}$ óptimo de 6,9 por lo que se inactiva en el estómago. Va aumentando con la edad.

Amilasa pancreática: tiene niveles bajos e inicia su actividad a los 4 meses, pero cuanto más almidones consuma, más aumentará. Esta limitación se compensa con la amilasa lingual y enzimas intestinales. Irá en aumento hasta los 13 años.

Glucoamilasa (maltasa), Glucoamilasa-maltasa, Isomaltasa: enzimas intestinales que tienen valores similares a los de niños de mayor edad o adultos, por lo que obtienen bien la glucosa a partir de almidón-amilopectina, almidón-amilosa y maltodextrinas.

Amilasa de la leche materna: resiste a la acidez del estómago y actúa en el intestino. Su actividad es similar a la amilasa salival y pancreática a esta edad. Permite obtener maltosa, maltotriosa y poca glucosa. 
Lactasa intestinal: suficiente para la digestión de la lactosa, su concentración es mayor que en el resto de la vida, lo que permite la óptima obtención de glucosa-galactosa.

Sacarasa intestinal: niveles similares al adulto (al nacer es 70\%) por lo que obtiene bien glucosa-fructosa a partir de sacarosa.

Trehalosa: valores de adulto, por lo que obtiene bien la glucosa a partir de trehalosa.

\section{Digestión de las proteínas $20,21,24,25,28$}

Las necesidades proteicas del recién nacido son mayores en relación con el peso corporal que en cualquier otra etapa, siendo de $2-2,5 \mathrm{~g} / \mathrm{kg}$ peso/día o un 7-12\% del valor calórico total. A pesar de la baja actividad de la pepsina gástrica la absorción es óptima.

Pepsina gástrica: es muy baja durante el primer año de vida y necesita un pH 1,5 a 4 para actuar (igual que el adulto). Pese a ello parece no ser un problema ya que las secreciones pancreáticas son suficientes para hidrolizarlas.

Ácido clorhídrico: tiene un $50 \%$ del valor adulto. A los 3 meses ya tiene $1 \mathrm{mEq} / \mathrm{H} / \mathrm{Kg}$ (valor mínimo para un adulto) y a los 6 meses, $2 \mathrm{mEq} / \mathrm{H} / \mathrm{Kg}$, por lo tanto entre los $4-6$ meses alcanza los valores del adulto.

Gastrina: valores normales o elevados.

Peptidasas pancreáticas (tripsina, elastina y quimotripsina): comparables o superiores a los adultos.

Sistemas de transporte de aminoácidos de membrana: tiene unas concentraciones más altas que en el resto de la vida.

\section{Otros datos de interés $\mathbf{s}^{7}, 20,22-24,26,27,29,30$}

Factor intrínseco (FI): a partir de los 6 meses comienza a absorberse la vitamina B12 apropiadamente, antes no. Se nace $\sin \mathrm{Fl}$, e irá en aumento hasta alcanzar valores del $100 \%$ del adulto para asegurar la absorción de vitamina B12.

Reflujo gastroesofágico (RGE): es un proceso fisiológico normal que presentan el $50 \%$ de los bebés y que desaparece espontáneamente entre los 6-12 meses.

Enteroquinasa intestinal: la secreción es insuficiente hasta que alcanza el primer año de vida.

Tripsina: niveles adecuados, similares a los de un niño de 2 años.

Péptidos regulatorios: producen una respuesta neuroendocrina madura que le permite alimentarse con leche desde el nacimiento.
Peristaltismo: $1 / 3$ parte que la del adulto.

Cólicos y diarreas postprandiales: deberían haber cesado.

Inmunidad digestiva: es capaz de sintetizar células plasmáticas en la lámina del tubo digestivo, como las IgAs que predominan en un $85 \%$ y van en aumento hasta los 2 años. El resto de IgM e IgG en una proporción de 20:3:1. Importante tenerlo en cuenta, para la elección de alimentos alergénicos.

Microbiota: con la introducción de alimentos distintos a la leche materna, la flora bacteriana se modifica, las bifidobacterias continúan siendo predominantes, pero aumentan la enterobacterias (Klebsiella, Enterobacter y E. Coli), así como otras bacterias. La relación bacterias anaerobias : aerobias es de 100:1

Filtración glomerular (FG): es inmadura durante el primer año. A los 3 meses tienen $60-70 \mathrm{~mL} / \mathrm{min} / 1,73 \mathrm{~m}^{2}$ que aumenta $100-110 \mathrm{~mL} / \mathrm{min} / 1,73 \mathrm{~m}^{2}$ a los 12 meses. Según las guías KDIGO 2013, a los 3 meses la FG equivale a un estadio 2 de Enfermedad Renal Crónica (ligero descenso de FG), ya que los valores normales son $>90 \mathrm{~mL} / \mathrm{min} / 1,73 \mathrm{~m}^{2}$.

Capacidad del estómago: a los 12 meses es de $300 \mathrm{~mL}$ para la mayoría de los bebés, se puede personalizar su cálculo aplicando $30 \mathrm{~mL} / \mathrm{kg}$ peso.

\section{A partir de los 12 meses $^{20-22,31}$}

Sales biliares: la concentración continúa siendo baja en comparación a la de un niño mayor o adulto.

Pepsina gástrica: alcanza los valores de adulto entre los 24 y 36 meses, al igual que las IgAs, por lo que son más eficientes para luchar contra antígenos o microbios, de la misma manera se reduce el riesgo de sensibilización y autoinmunización ante agentes ambientales.

A partir de los 36 meses $20,22,25,26,32$

Se completa la maduración digestiva de:

Tripsina, quimotripsina, carbopeptidasa y enteroquinasa, ácido estomacal y células inmunológicas (con la migración completa hacia el tubo digestivo).

\section{EVLUCIÓN DEL RITMO DE DENTICIÓN \\ EVOLUCIÓN DEL RITMO DE DENTICIÓN DEL LACTANTE}

Ofrecer una textura u otra también está relacionado con la aparición de los dientes, ya que la función de éstos es 
preparar los alimentos para facilitar la digestión. Cuanto más triturado esté el alimento más posibilidad hay de ponerse en contacto con la amilasa o lipasa salival de la boca para iniciar la digestión de una forma óptima. Tanto si les ha salido algún diente como si no, esta función masticatoria la asumen sus encías. Pero éstas no permiten cortar alimentos, sólo moler. Por este motivo, los alimentos para comer con las manos deben ser muy blandos, o bien que se puedan reblandecer a medida que los van chupando. También hay que tener en cuenta que la aparición de los dientes está relacionada con el crecimiento y con la lactancia materna, ya que ésta influye en la erupción temprana de los mismos pudiendo ello suponer una ventaja evolutiva ${ }^{33}$.

En la Tabla 1 presentamos el ritmo de dentición para que puedas hacer unas recomendaciones más personalizadas a cada bebé.

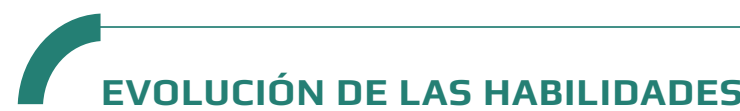
PSICOMOTORAS DEL LACTANTE

El desarrollo psicomotor es el área de estudio que analiza tanto la madurez psicológica como la muscular. Se clasifica en:

- Perceptivo-manipulativa: es aquella que permitirá que el bebé mantenga firme la cabeza, permanezca sentado y pueda hacer giros con todo su cuerpo.

- Cognitiva: se relaciona con la motricidad fina, importante para poder comer y manipular los alimentos con las manos o los cubiertos, así como para poder coger varios alimentos a la vez o dejar uno para coger otro.

Tabla 1. Ritmo de dentición ${ }^{30,34}$.

\begin{tabular}{|c|c|c|}
\hline \multicolumn{3}{|r|}{ Ritmo de dentición } \\
\hline Edad & Clase & Funcionalidad \\
\hline 4 a 6 meses & Encías & $\begin{array}{l}\text { Hasta la salida de los primeros dientes, muerden con sus duras encías, } \\
\text { aunque de forma ineficiente. Si el bebé es capaz de comer a trozos deben } \\
\text { ser muy blandos, fáciles de masticar y que se deshagan en la boca. } \\
\text { Dependiendo de la textura que se ofrezca se desarrollará con más o menos } \\
\text { velocidad esta respuesta de masticar con las encías. }\end{array}$ \\
\hline 6 - 10 meses & $\begin{array}{l}\text { Incisivos } \\
\text { (8 unidades) }\end{array}$ & $\begin{array}{l}\text { Ya puede cortar alimentos de forma más eficiente (alimentos blandos } \\
\text { y semiblandos), además de continuar con purés y alimentos fáciles de } \\
\text { masticar y que se deshagan en la boca. }\end{array}$ \\
\hline 12 meses & \multicolumn{2}{|c|}{$\begin{array}{l}\text { La mayoría tiene } 6 \text { y } 8 \text { unidades. } \\
\text { Si no es el caso de su paciente, mejor que lo consulte con el pediatra ya que hay varias causas. A priori nc } \\
\text { es preocupante, sobre todo si van apareciendo en orden. }\end{array}$} \\
\hline 14 meses & $\begin{array}{l}\text { Molares de leche } 1 \\
\text { (4 unidades) }\end{array}$ & $\begin{array}{l}\text { Sirven para moler los alimentos un poco más duros. Como aún no tienen } \\
\text { el segundo molar es mejor evitar los muy duros, sobre todo aquellos } \\
\text { pequeños y redondos por riesgo de asfixia. }\end{array}$ \\
\hline 18 meses & $\begin{array}{l}\text { Caninos } \\
\text { (4 unidades) }\end{array}$ & $\begin{array}{l}\text { Sirven para desgarrar alimentos, como hincarle el diente a un bocadillo o } \\
\text { desgarrar un trozo de jamón... }\end{array}$ \\
\hline 2 a 3 años & $\begin{array}{l}\text { Molares de leche } 2 \\
\text { (4 unidades) }\end{array}$ & $\begin{array}{l}\text { Son más grandes que los anteriores y también sirven para triturar los } \\
\text { alimentos, facilitarán la molienda y la emulsión con la ptialina. }\end{array}$ \\
\hline 3 años & \multicolumn{2}{|c|}{$\begin{array}{l}\text { Dentición completa con } 20 \text { unidades de dientes de leche. } \\
\text { Ya son bastante eficientes comiendo, pero los alimentos con riesgo de atragantamiento o asfixia es mejo } \\
\text { esperar hasta los } 4 \text { años. }\end{array}$} \\
\hline
\end{tabular}

En esta tabla se indica un rango de edad de 4 a 6 meses para las encías, ya que existe un consenso de la European Society for Paediatric Gastroenterology, Hepatology and Nutrition (EPSGHAN) en el cual se posicionan diciendo que la introducción de nuevos alimentos no debe ser antes de los 4 meses, ni más tarde de los 6 meses (26 semanas o antes de cumplir el $7^{\circ}$ mes). Para que se tenga en cuenta, en casos clínicos puntuales que necesiten de una ingesta temprana. Pero insistimos que la edad óptima para iniciar el beikost son los 6 meses marcados por la Organización Mundial de la Salud (OMS) y la Asociación Española de Pediatría (AEP). Además, en la mayoría de casos la lactancia materna o en su defecto de fórmula o mixta debería ser exclusiva mínimo hasta los 6 meses y alargándose hasta los 2 años o más ${ }^{3}$. 
- Lenguaje: permitirá al bebé comunicarse mejor con sus cuidadores para transmitir sus necesidades o preferencias alimentarias.

- Social: hace referencia a su capacidad de expresar sentimientos de agrado o disgusto durante el acto de comer o de experimentar con la comida y de entender las órdenes de sus padres.

Siguiendo esta clasificación Gesell A. diseñó un diagrama que representaba las tendencias generales en el desarrollo conductual desde la concepción hasta la edad de 5 años. A través de esta información se puede analizar el desarrollo conductual del bebé, de una forma sistemática y exacta a través de 4 clasificaciones: motora gruesa, adaptativa, lenguaje y personal-social. Las fases de desarrollo para el lactante de 4 a 12 meses se encuentran en la Tabla 2 junto a la información de otras fuentes consultadas.

Por otro lado, Briolotti et al. (2015) comentan a partir de los estudios de Gesell A. que: "el bebé debería seguir su propio ritmo de desarrollo y para ello se debería facilitar las mejores condiciones posibles para que el bebé se autoregule y se autoadapte, teniendo en cuenta que la cultura y el ambiente propicia tanto a ayudar, estimular y dirigir como a retrasar y desanimar ${ }^{\prime \prime 35}$.

El estudio aleatorizado y controlado de Daniels L. et al. ${ }^{11}$ tiene la hipótesis de que "la autoalimentación a lo largo del período de alimentación complementaria puede ayudar a los bebés a mantener y desarrollar las habilidades de autorregulación de la energía que han desarrollado al alimentarse exclusivamente con leche y que este comportamiento continuará en la infancia posterior". Esta autoalimentación hace referencia a comer con cubiertos o con las manos y hacerlo de esta última forma además les permite experimentar con la comida, tal y como fomenta el método BLW o BLISS. Método que además tiene otros beneficios como estimular todos los sentidos, fomentar la psicomotricidad tanto gruesa como fina y el proceso de masticación temprano, mejorar la capacidad de hablar, y también consigue que los bebés no tengan tantos problemas con la comida y un peso más óptimo ${ }^{16,36-40}$.

D'Auria E. et al., en su revisión sistemática de 2018, comenta que existen diferentes desarrollos psicomotores a los 6 meses, que hacen que unos bebés estén más preparados que otros para comer sólo con sus manos. Y que la capacidad de movilizar el alimento por la boca (ya sea masticando trozos blandos o triturado) también puede ser distinta entre niños de distintas edades ${ }^{17}$.

Existe gran variedad de edades para alcanzar los hitos motores, perfectamente compatibles con un normal crecimiento, pero gran parte de los niños los desarrollan alrededor de un momento determinado, esto lo demostró Carruth $^{41}$, quien diseñó un estudio transversal, en forma de encuesta telefónica, donde los cuidadores informaban periódicamente de la evolución de los hitos de maduración, las habilidades para la autoalimentación, el número de dientes y la ingesta de energía y nutrientes. El seguimiento se realizó a 3.022 niños, con edades comprendidas entre los 4 y los 24 meses de edad. Las edades en las que se mostraron los hitos en el desarrollo y la erupción de los dientes se encontraban dentro del rango de edad esperado, dichos datos podemos verlos en la Tabla 3.

Tabla 2. Capacidades y desarrollo psicomotor $27,30,41-45$.

\section{Capacidades y desarrollo psicomotor}

4-6 meses Los bebés sostienen y mueven la cabeza.

Hacen esfuerzos para agarrar alimentos y mirar lo que tienen en su mano.

Persiguen la comida con la mirada.

Abren la boca para recibir comida.

Reconocen el biberón.

Pueden abrir la boca ante una cuchara, antes de que se inicie la alimentación complementaria.

Tienen una regulación total del apetito.

$1 / 3$ de los bebés, se sientan con algo de apoyo.

El $95 \%$ puede sentarse con la cabeza estable.

Intentan agarrar los alimentos pero cierran las manos antes o después de tiempo.

5 meses:

Inicio del movimiento de masticación. Son capaces de sujetar la cuchara pero no para autoalimentarse. 


\begin{tabular}{|c|c|}
\hline \multicolumn{2}{|r|}{ Capacidades y desarrollo psicomotor } \\
\hline 6 meses & $\begin{array}{l}\text { Desaparece el reflejo de extrusión. } \\
\text { Pueden mover los alimentos de un lado a otro de la boca (desde la introducción de los sólidos } \\
\text { grumosos). } \\
\text { Pueden morder, disolver y masticar alimentos suaves. } \\
\text { Comienzan a masticar de forma vertical pequeños trozos de alimentos. } \\
\text { El 50\% pueden sentarse sin apoyo. } \\
\text { La mayoría suele alcanzar, tomar y sostener alimentos de un tamaño adecuado a sus manos, un } \\
\text { biberón o taza. } \\
\text { Si se ofrecen trocitos suaves grandes, muchos de los bebés cerrarán la boca a esta edad. } \\
\text { Entre los } 6-12 \text { meses: } \\
\text { El reflejo de cerrar la boca como una mordaza va disminuyendo. } \\
\text { Antes de los } 7 \text { meses: } \\
\text { Necesitan la ayuda de los padres para que limpien la cuchara haciendo un movimiento de inclinación } \\
\text { hacia arriba, aunque si lo hacen solos no derraman mucho. } \\
\text { Distinguen bien los distintos sabores (dulce, ácido, amargo, salado) y muestran su agrado o desagrado } \\
\text { hacia ellos. }\end{array}$ \\
\hline 6-9 meses & $\begin{array}{l}\text { 6-8 meses: } \\
\text { Pueden succionar líquido de una taza. } \\
\text { Entre los 6-9 meses: } \\
\text { Dominan el tronco y sus manos. } \\
\text { Una vez sentados se pueden inclinar hacia delante apoyando sus manos. } \\
\text { Pueden agarrar y traspasar alimentos y vajilla de una mano a la otra. } \\
\text { Manifiestan expectativas a la hora de comer. } \\
\text { Entre los 7-8 meses. } \\
\text { El 77\% pueden cerrar los labios superiores para limpiar la cuchara sin derramar mucho. } \\
\text { Aparecen los primeros incisivos. } \\
\text { Comienzan a masticar y hacer movimientos de masticación giratorios. } \\
\text { Adquieren la capacidad de sentarse sin apoyo permitiendo mayor movimiento de brazos para alcanzar } \\
\text { alimentos con los dedos o la cuchara. } \\
\text { Pueden dar uno o dos tragos de una taza sostenida por el padre. } \\
\text { El } 95 \% \text { pueden sentarse sin apoyo. } \\
\text { Pueden pasar la cuchara o alimento de una mano a otra. } \\
\text { Entre los } 8-9 \text { meses: } \\
\text { Se sientan solos y son capaces de soltar los alimentos de la mano de una forma voluntaria. } \\
\text { Entre los 8-12 meses: } \\
\text { Pueden cortar alimentos un poco más duros (cuando los incisivos centrales han salido). } \\
\text { Intentan comer con cuchara torpemente. } \\
\text { Comienzan a beber de una taza cerrada. } \\
\text { Pueden alimentarse con sus manos, enfrentarse a alimentos sólidos más duros, así como adelantar la } \\
\text { cabeza rápidamente para comer lo que se le ofrece en cuchara. }\end{array}$ \\
\hline $9-12$ meses & $\begin{array}{l}\text { Dominan mejor la pinza (dedo índice y pulgar). } \\
\text { Se inicia el agarre de pinza con el dedo índice y el pulgar. } \\
\text { Entre los } 9-10 \text { meses: } \\
\text { Pueden beber en taza sostenida por ellos solos. } \\
\text { Entre los } 9-11 \text { meses: } \\
\text { El 97\% de los bebés se sienta sin apoyo. } \\
\text { Muestran interés claro por alimentarse por sí mismos. } \\
\text { Logran coger la cuchara por sí solos sin derramar mucho. }\end{array}$ \\
\hline
\end{tabular}




\section{Capacidades y desarrollo psicomotor}

\section{9-12 meses Entre los 11-12 meses:}

Empiezan a beber de una taza abierta.

Se alimentan por sí mismos.

Reconocen la comida por la vista, el olfato y el sabor.

Pueden hacer frente a la mayoría de las texturas, pero no son totalmente maduros para masticar.

Mastican y realizan los movimientos masticatorios de forma más eficaz.

\section{Al final del año y hasta los 2 años:}

Mejoran su motricidad fina para coger cosas con los dedos, así, primero comerán con las manos, luego con los dedos y finalmente con los utensilios.

\section{2 meses Pueden apilar alimentos.}

Son capaces de sostener la taza solos y beber 4 a 5 sorbos.

El 91\% de los niños usan una taza con asas y tapa sin ayuda.

Los bebés que toleran los grumos a los 6 meses, a los 12 mastican con eficacia.

\section{De 1 a 4 años:}

Van aceptando todo tipo de texturas pero de forma progresiva, ya que su masticación no es $100 \%$ eficiente.

14-15 meses Los bebés imitan la conducta alimentaria y se animarán a probar alimentos nuevos si un adulto lo intenta en primer lugar.

El $64 \%$ de los niños usan la cuchara sin derramar mucho

El $34 \%$ beben en un vaso abierto y sin asas de $100 \mathrm{~mL}$.

1-2 años Los bebés imitan a los padres comiendo de forma más exacta que en los meses anteriores.

18 meses:

A esta edad los bebés corren, saltan... por lo que es importante que coman sentados para evitar el atragantamiento.

\section{9 meses:}

Pueden comer solos con cuchara.

2 años

Los bebés imitan a los padres y lo que hacen los demás niños que lo rodean.

Toleran la mayoría de alimentos familiares, siempre que se le haya enseñado a comer correctamente una dieta variada y sana.

El $97 \%$ de los bebés saben limpiar la cuchara con el labio superior.

Las preferencias a esta edad predicen las preferencias a lo largo de la vida.

3-4 años Los niños cambian sus preferencias alimentarias para asemejarse a otros compañeros de clase.

A los 4 años:

Ya no hay peligro de atragantamiento. Son tan hábiles masticando como un adulto, aunque siempre hay que vigilar que coman sentados y no de pie o jugando, ya que un mal gesto o tropiezo puede hacer que se atraganten independientemente de la textura del alimento.

Se ha incluido el desarrollo psicomotor a la edad de 4-6 meses por la misma razón que se ha comentado en la Tabla 1 de ritmo de dentición.

Por otro lado, se ha analizado el desarrollo psicomotor de bebés prematuros para determinar si estos bebés podrían aplicar el mismo tipo de texturas y se han encontrando los siguientes estudios:

Eickmann S.H. tomó una muestra de 135 bebés de 6 a 12 meses, 45 pretérmino y 90 a término, sin presencia de infecciones congénitas $\mathrm{y} / \mathrm{o}$ malformaciones y síndromes genéticos, tuvieron todos una puntuación cognitiva, motora y motoras medias superiores a 100 y no encontraron diferencias significativas en ambos grupos ${ }^{46}$.

Perez-Pereira compara 150 bebés prematuros con 49 bebés a término y encontraron diferencias significativas en motricidad, rango de estado y regulación de estado. Aunque no fueron necesariamente a favor de los a término ya que las 
Tabla 3. Adquisición de las habilidades psicomotoras en lactantes de 4 a 24 meses según el estudio Carruth 200441,46.

\begin{tabular}{|c|c|c|c|c|c|c|}
\hline Habilidades psicomotoras & $\begin{array}{c}\text { 4-6 } \\
\text { meses }\end{array}$ & $\begin{array}{c}\text { 7-8 } \\
\text { meses }\end{array}$ & $\begin{array}{c}9-11 \\
\text { meses }\end{array}$ & $\begin{array}{l}12-14 \\
\text { meses }\end{array}$ & $\begin{array}{l}15-18 \\
\text { meses }\end{array}$ & $\begin{array}{l}19-24 \\
\text { meses }\end{array}$ \\
\hline $\begin{array}{l}\text { Sujeción de la comida } \\
\text { con la mano }\end{array}$ & $68 \%$ & $96 \%$ & $98 \%$ & NR & NR & NR \\
\hline $\begin{array}{l}\text { Retirar la comida } \\
\text { de la cuchara con los labios } \\
\text { sin derramar mucho }\end{array}$ & NR & $77 \%$ & $88 \%$ & $90 \%$ & $96 \%$ & $97 \%$ \\
\hline $\begin{array}{l}\text { Uso de la cuchara sin } \\
\text { derramar mucho }\end{array}$ & NR & $5 \%$ & $11 \%$ & $29 \%$ & $64 \%$ & $88 \%$ \\
\hline $\begin{array}{l}\text { Uso de taza con } \\
\text { asas y tapa sin ayuda }\end{array}$ & NR & $42 \%$ & $70 \%$ & $91 \%$ & $96 \%$ & 99\% \\
\hline $\begin{array}{l}\text { Uso de un vaso } \\
\text { normal de } 100 \mathrm{~mL}\end{array}$ & NR & NR & $10 \%$ & $14 \%$ & $34 \%$ & $57 \%$ \\
\hline $\begin{array}{l}\text { Come alimentos } \\
\text { que necesitan masticarse }\end{array}$ & NR & $53 \%$ & $87 \%$ & $95 \%$ & 99\% & 99\% \\
\hline
\end{tabular}

madres fumadoras influenciaron negativamente. Por lo que no se encontró retraso en general en la maduración de estos bebés prematuros ${ }^{47}$.

En 125 bebés de ambos sexos, menores de 12 meses, nacidos a pretérmino y seleccionados aleatoriamente, se evaluaron las 4 áreas de desarrollo: perceptivo-manipulativo, cognitivo, lenguaje y social a partir de la Escala de BrunetLézine. Y se determinó que el perfil de desarrollo psicomotor de los lactantes tenía un evidente retraso sobre todo del segundo al quinto mes. Aunque entre los 9-11 meses aumenta el número de bebés con puntuaje normal. También vieron cómo el desarrollo en las diferentes áreas no era igual ${ }^{48}$. Remundo A. recomienda la importancia de la estimulación en los primeros 12 meses. La importancia de hacer una buena valoración del desarrollo psicomotor para determinar alguna alteración y evitar sobreproteger a los prematuros evitando que exploren y manipulen objetos. Los resultados de esta investigación se encuentran en las Tablas 4 y 5 .

Tabla 4. Control postural ${ }^{47}$.

\begin{tabular}{l|c|c|c|c|c|c|c|c}
\hline Edad en meses & 4 & 5 & 6 & 7 & 8 & 9 & 10 & 11 \\
\hline No muestra & 19 & 20 & 14 & 6 & 9 & 10 & 5 & 1 \\
\hline \% Alto & 5 & 0 & 0 & 17 & 0 & 10 & 20 & 0 \\
\hline \% Normal & 32 & 70 & 50 & 33 & 67 & 80 & 60 & 100 \\
\hline \% Retraso leve & 42 & 25 & 21 & 50 & 22 & 10 & 20 & 0 \\
\hline \% Retraso moderado & 5 & 0 & 14 & 0 & 0 & 0 & 0 & 0 \\
\hline \% Retraso grave & 11 & 0 & 14 & 0 & 11 & 0 & 0 & 0 \\
\hline \% Retraso severo & 5 & 5 & 0 & 0 & 0 & 0 & 0 & 0 \\
\hline
\end{tabular}

Analiza el desarrollo neurológico y hace referencia a los movimientos corporales, reacciones posturales, mantenimiento de la cabeza, capacidad de sentarse y pararse destreza para aproximarse a un objeto entre otras actividades de movilización, coordinaciones motrices que le permiten hacer pequeñas orientaciones espaciales. 
Tabla 5. Coordinación óculo-motriz $(\%)^{47}$.

\begin{tabular}{|l|c|c|c|c|c|c|c|c|}
\hline Edad en meses & 4 & 5 & 6 & 7 & 8 & 9 & 10 & 11 \\
\hline No muestra & 19 & 20 & 14 & 6 & 9 & 10 & 5 & 1 \\
\hline \% Alto & 5 & 0 & 0 & 0 & 11 & 0 & 20 & 0 \\
\hline \% Normal & 11 & 50 & 29 & 83 & 56 & 80 & 60 & 100 \\
\hline \% Retraso leve & 32 & 20 & 50 & 0 & 22 & 10 & 20 & 0 \\
\hline \% Retraso moderado & 26 & 15 & 0 & 17 & 0 & 10 & 0 & 0 \\
\hline \% Retraso grave & 0 & 10 & 21 & 0 & 11 & 0 & 0 & 0 \\
\hline \% Retraso severo & 26 & 5 & 0 & 0 & 0 & 0 & 0 & 0 \\
\hline
\end{tabular}

Hace referencia a las adaptaciones senso-motrices ante objetos y situaciones que le permiten descubrir el mundo que le rodea. Como la coordinación de movimiento oculares y manuales para alcanzar y manipular objetos.

Cristancho L. et al..$^{49}$ analizó a 118 bebés entre 1 y 24 meses. El promedio de edad era de 6,4 meses, con riesgo leve para alteración en un $34 \%$, riesgo alto en un $7 \%$ de los lactantes y el $59 \%$ desarrollo normal. A nivel general el $27,3 \%$ tuvo una afectación del sistema motor fino y el $25 \%$ a nivel cognitivo y de lenguaje en todas las etapas. A los 4 meses un $12 \%$ no presentaba algunas de las reacciones del desarrollo que se esperaban y en un $6 \%$ hubo signos de alarma. Los resultados se encuentran en la Tabla 6.
Se debe tener en cuenta que, según el estudio Carruth, en la mayoría de casos existe una correlación entre el aumento de consumo de energía y nutrientes y el desarrollo temprano a alimentarse ( 7 a 14 meses), aunque en todos los casos el aporte fue adecuado. Las habilidades de autoabastecimiento se consiguen entre los 15 y 18 meses, independientemente del método con el que empezaran a comer.

Tabla 6. Riesgo de alteraciones en el desarrollo neuroconductual.

\begin{tabular}{|c|c|c|c|}
\hline Edad & Acción & \% Sí lo consiguen & \% No lo consiguen \\
\hline \multirow[t]{4}{*}{4 meses } & No rechaza la papilla, succión enérgica & 100 & $0 \%$ \\
\hline & Llevarse cosas a la boca & 93,88 & 6,1 \\
\hline & Intenta tocar objetos & 91,84 & 8,2 \\
\hline & No le molesta la posición & 85,71 & 14,3 \\
\hline \multirow[t]{3}{*}{8 meses } & Come una galleta solo & 86,36 & 13,6 \\
\hline & Se mantiene sentado sin ayuda & 95,65 & 4,3 \\
\hline & Toma un objeto en cada mano & 90,48 & 9,5 \\
\hline \multirow[t]{2}{*}{12 meses } & Bebe solo en taza & 90,91 & 9,1 \\
\hline & Presión fina & 96,88 & 3,1 \\
\hline 18 meses & Come solo con cuchara aunque derrame & 100 & 0 \\
\hline \multirow[t]{3}{*}{24 meses } & $\begin{array}{l}\text { Es capaz de abrir un plátano o desenvolver un } \\
\text { alimento con envoltorio }\end{array}$ & 90 & 10 \\
\hline & Y se come el plátano que ha pelado & 90,91 & 10 \\
\hline & Imita lo que hacen los padres & 100 & 0 \\
\hline
\end{tabular}




\section{ANÁLISIS DEL BLW Y BLISS VERSUS EL MÉTODO CLÁSICO EN RELACIÓN A LA ASFIXIA Y TEXTURAS}

La OMS recomienda que la introducción de alimentos diferentes a la lactancia sea a los 6 meses, iniciando con purés y pasando a comer trozos hacia los 8 meses, aunque países como Reino Unido y Nueva Zelanda lo hacen a los 6 y 7 meses, respectivamente.

Arden M.A. y Abbott R.L. ${ }^{13}$ refieren cómo hay bebés que pese a ofrecerles alimentos siguiendo el BLW no los tragaban hasta más adelante.

Daniels L. et al. ${ }^{11}$ explican que si no se modifica el BLW adecuándolo al método BLISS podrían existir deficiencias de hierro, zinc, bajada de peso y posibles atragantamientos. Pero los resultados del estudio aún no se han publicado.

Morison B.J. et al. ${ }^{14}$ concluyen que la ingesta energética entre el grupo que usaba el método BLW y el clásico de potitos era similar, pero el grupo de BLW ingería un exceso de grasa y sobre todo de grasa saturada y menor en hierro, zinc y B12. Pero en ambos grupos se ofrecían alimentos con riesgo de atragantamiento.

Fangupo L.J. et al. en el 2016, tras su estudio, comentan que: "Los bebés que siguen un enfoque de alimentación dirigido por bebés (BLW, BLISS) y que incluyen consejos para minimizar el riesgo de asfixia no parecen ahogarse más que los bebés siguiendo prácticas de alimentación más tradicionales. Sin embargo, la gran cantidad de niños en ambos grupos que ofrecen alimentos que representan un riesgo de asfixia es preocupante" 50 .
En el estudio BLISS, observaron que se habían ofrecido alimentos con riesgo de asfixia en todos los grupos de edad. La asfixia se produjo al menos una vez en todos los grupos de destete. $35 \%$ en lactantes, $52 \%$ a los 7 meses y $95 \%$ a los 12 meses. Los alimentos con los que comúnmente se ahogaban incluían rodajas de manzana, galletas y salchichas ${ }^{6}$.

D'Auria E. et al., en su revisión sistemática del 2018, también coinciden en que no hay diferencia significativa entre el método dirigido por el bebé y el tradicional. En todos los casos la probabilidad de que suceda el atragantamiento es del $30 \%$. Aunque cabe decir que los padres no eran capaces de distinguir si se trataba de una arcada o de asfixia. Y que los estudios que encontraron alguna diferencia (11,9\% BLW estricto, $11,6 \%$ tradicional y $15,5 \%$ BLW flexivo) no eran de muy buena calidad metodológica ${ }^{17}$.

Williams L. et al. ${ }^{51}$ comentan que el método BLISS mejora algunas problemáticas del BLW, como reducir la ingesta de grasa saturada. Pero tanto en este método como en el tradicional se encontró un exceso en el consumo de sodio y azúcares.

\section{$\longrightarrow$ \\ TEXTURAS EVOLUTIVAS \\ Teniendo en cuenta todo lo anteriormente mostrado y ba- sándonos en las recomendaciones de organismos oficiales y la evidencia científica, proponemos la siguiente tabla evolu- tiva, donde comenzaremos por los purés espesos e iremos cambiando texturas hasta alcanzar la alimentación del res- to de la familia (Tabla 7).}

Tabla 7. Texturas evolutivas en bebés que están preparados para comer 8,30,36,37,43,52-60.

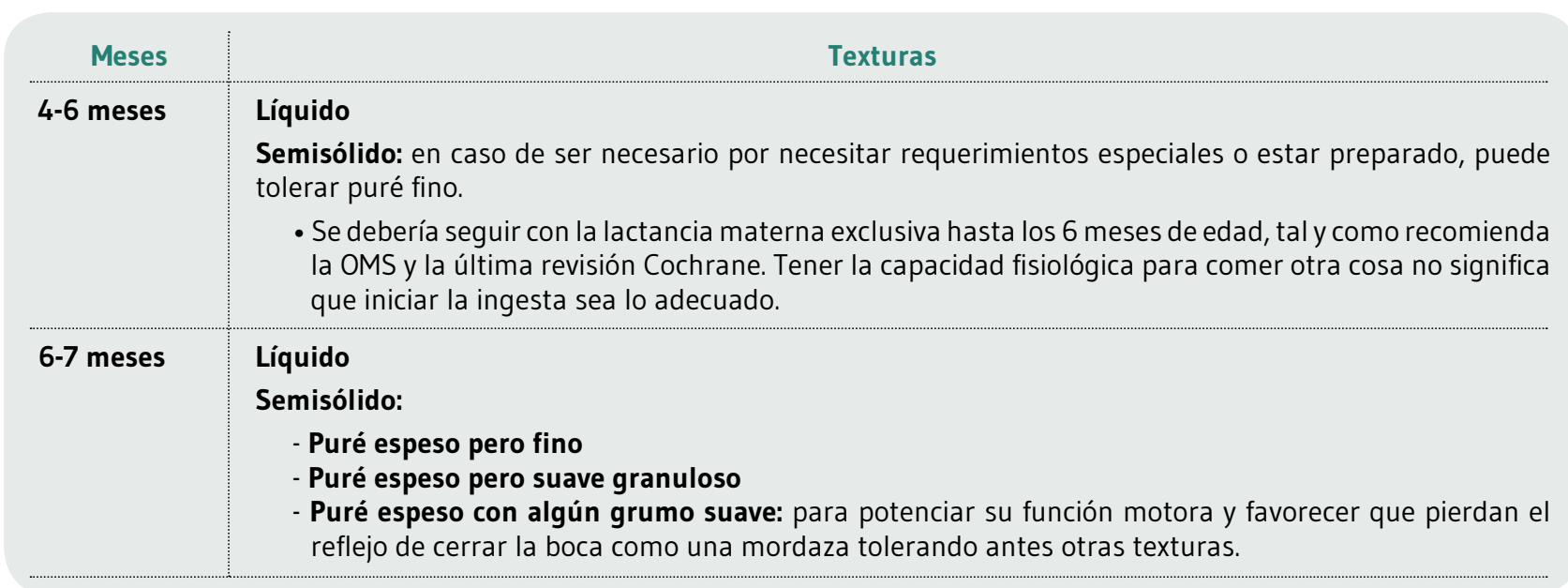




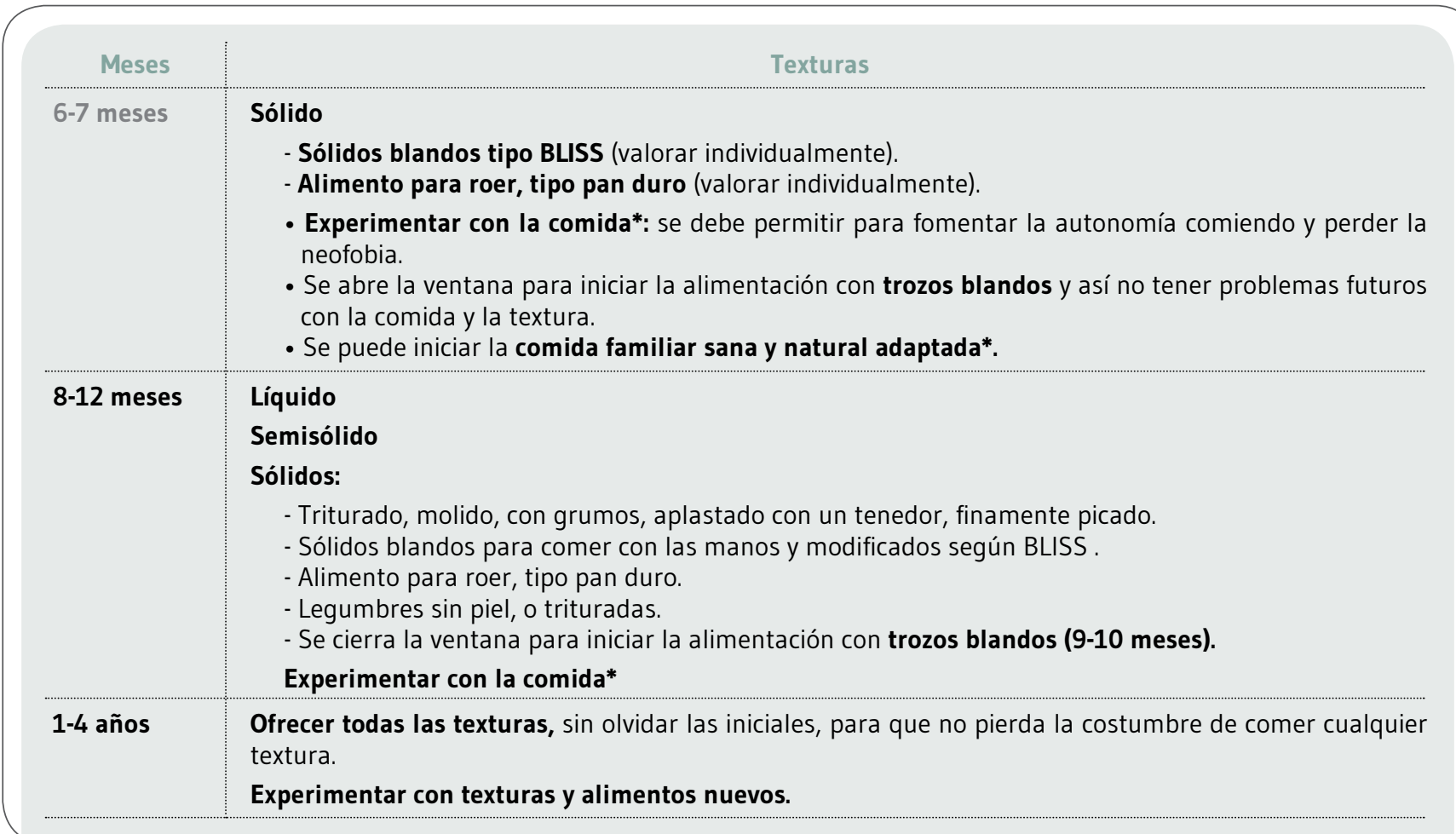

Se ha añadido posibles texturas evolutivas a los 4-6 meses por el mismo motivo comentado en la Tabla 1 (Ritmo de dentición) y Tabla 2 (Capacidades y desarrollo psicomotor).

* Explicado con más detenimiento en el apartado siguiente: ¿Cómo cocinar o presentar las distintas texturas?

Se debe considerar que todas las edades y rangos de edad de este cuadro, son orientativas. Dependerán de las habilidades innatas del bebé y de la interacción del mismo con el entorno ${ }^{30}$, ya que hay bebés que están preparados para comer antes de los 6 meses y otros que tardaran algo más. El hecho de que fisiológicamente puedan estar preparados para comer alimentos diferentes de la leche, no significa que se deba fomentar la introducción de estos alimentos antes del 60 mes, tal y como nos indica la OMS y la última revisión Cochrane ${ }^{60}$. Para apoyar a los bebés a que se desarrollen eficazmente, las texturas de los alimentos se deben modificar y adaptar a las necesidades individuales de cada bebé.

Antes de comenzar la alimentación complementaria, el bebé debe mostrarnos indicios de que está preparado para tal fin, algunas de las señales son ${ }^{56}$ :

- Tener alrededor de 6 meses de edad.

- Sentarse con apoyo y mantener la cabeza erguida.

- Desaparecer el reflejo de extrusión.

- Abrir la boca cuando se le ofrece con una cuchara.

- Girar la cara, en sentido de negación, si no quiere comida.

- Sentir atracción por coger alimentos con las manos.
Estimular el desarrollo de una masticación eficiente y completa durante los primeros años de vida aportará muchos beneficios, tanto en el momento actual como en la edad adulta, e influirá en el proceso de saciedad, en la mejor absorción de nutrientes así como en el desarrollo de la cavidad oral, tal y como apuntan Le Révérend, et al ${ }^{59}$.

Larsson $^{61}$, tras estudiar dos poblaciones de niños, en las cuales a unos se les administra pan duro para roer a partir de los 6 meses y a los otros se les alimenta con alimentos blandos durante 1 o 2 años, llega a la conclusión que existe correlación entre la consistencia de los alimentos y el desarrollo de la cavidad oral. Dicho resultado también lo apoya la comunidad de ortodoncia, quienes sugieren que los alimentos más blandos impiden el desarrollo muscular y óseo, y por lo tanto son responsables de muchas de las atrofias. Por lo tanto, siempre que el niño esté preparado, se podría ofrecer algún alimento para roer y así fomentar el desarrollo de la cavidad oral.

Se debe tener en cuenta que para que la aceptación de las nuevas texturas sea buena es importante que estén adaptadas a la capacidad de masticación del niño, así como 
exponer tempranamente y permitir que manipulen dichas texturas. Respecto al crecimiento orofacial, debemos tener en cuenta que no finaliza hasta los 18 años de edad; y si ofrecemos diversas texturas durante el destete, y no sólo purés, ayudamos a que dicho crecimiento se desarrolle con mayor facilidad $^{8,59}$.

Desde el inicio de la alimentación complementaria se debe fomentar la inclusión de los mismos alimentos que consume el resto de la familia, siempre y cuando éstos sean saludables, con la puntualización de la textura, forma de presentación y exclusión de sal, azúcar, picantes, etc.

\section{$\longrightarrow$ ¿CÓMO COCINAR O PRESENTAR LAS DISTINTAS TEXTURAS?}

Los sistemas culinarios que a continuación se explican, únicamente hacen referencia a cómo conseguir cada textura evolutiva, no tienen en cuenta qué tipo de ingredientes se escogen, si son buenas combinaciones para potenciar la digestibilidad y absorción de nutrientes, o cómo cocinar los alimentos para que haya la mínima pérdida nutricional posible y que al mismo tiempo sean salubres y con la mínima o nula contaminación derivada de los alimentos o del sistema de cocción usados.

\section{Herramientas culinarias}

Para preparar la comida del bebé se pueden utilizar distintos instrumentos como son: batidora, picadora, molinillo de café, pasapurés con distintas cuchillas para variar la textura, tamiz, colador, mortero, gasas de algodón, platos y tenedor.

\section{Texturas evolutivas}

\section{Líquido}

Leche materna, leche de fórmula, agua de baja mineralización (50-500mg/L de residuo seco) y otros líquidos sanos como caldos, zumos de frutas naturales con su fibra, batidos caseros nada o poco dulces... Las infusiones o sueros fisiológicos sólo se usaran en ocasiones clínicas y bajo supervisión médica.

\section{Semilíquido}

En la mezcla se usa más líquido (leche materna o de fórmula, agua de la cocción, caldo, zumo natural) que alimento sólido. Se cocina, si es preciso, se tritura finamente y se pasa por una gasa de algodón y se exprime con las manos limpias o se pasa por un colador de agujeros finos y se pica con un mortero.

\section{Semisólido}

Puré espeso pero suave: se elimina el líquido sobrante de haber cocinado la mezcla y se tritura dicha mezcla hasta que quede muy fino. Si lo agarras con una cuchara y la mueves, el contenido no se cae con facilidad. Normalmente se consigue con tubérculos o frutas no granulosas como el boniato, patata, plátano...

Puré espeso pero suave y granuloso: igual que la textura anterior, pero escogiendo alimentos que por su naturaleza ya nos dé esta textura granulosa, como sería el caso de triturar una manzana en lugar de un plátano. Si se necesita espesar la textura de frutas trituradas se puede añadir papillas de cereales o bien poner el puré en un colador para que filtre el líquido sobrante dando unos golpecitos contra el cuenco.

Puré muy espeso pero suave con algún grumo57: el procedimiento es el mismo que el anterior, pero se reserva una parte para ser triturada bastamente y la otra parte se tritura finamente para que quede más cremoso. A continuación, se mezclan ambos en el mismo recipiente. También puedes reservar un poco de la mezcla y machacarla con el mortero o tenedor y luego mezclar con el puré fino ${ }^{36}$, o bien reservar la carne o pescado y desmenuzarlo, o picar lo por separado para luego mezclarlo con el puré espeso pero fino. Si lo agarras con una cuchara y la giras no se debe caer el contenido, debe ser una textura agradable que no se quede encallada en el cuello.

\section{Sólidos blandos tipo BLISS}

Son aquellos alimentos blandos que se pueden agarrar con las manos, como alimentos al vapor o de consistencia suave o madura, cortados en forma alargada o triangular y lo suficientemente grandes para que el bebé los pueda agarrar y comer sin tener que abrir la mano ${ }^{62}$, p.e.: un arbolito de brócoli al vapor, una tiras de tofu, plátano pelado dejando la piel abajo para que el agarre sea mejor, pan sin sal, triángulos de queso semicurado; recetas que se hayan adaptado para poder comer con las manos, cocinadas a la plancha o al horno, p.e.: hamburguesas, croquetas, bolas, empanadillas, palitos, bocadillos... todos ellos caseros y con ingredientes sanos, teniendo en cuenta tanto versiones vegetales como animales.

Para que corresponda con el método BLISS es necesario que en cada comida se ofrezca, al menos, un alimento de cada uno de los siguientes grupos: alimentos ricos en hierro, alimentos ricos en energía y una fruta o verdura ${ }^{11}$.

Trocitos: carne, pescado, huevo o tofu cocido que esté blando y cortarlo en tamaños de como mínimo 1,3cm para evitar 
problemas de atragantamiento o bien desmenuzado con las manos ${ }^{36}$.

\section{Comida en familia adaptada}

Significa que todos los miembros de la familia comen lo mismo pero que se cambian algunos condimentos como especias, cantidad de sal y salsa o bien cuando al plato de la familia simplemente se le aplica alguna técnica culinaria como: aplastar con un tenedor, triturar, picar, desmenuzar, cortar... para facilitar la masticación del bebé ${ }^{37}$. Los niños pequeños en sus inicios se cansan de masticar y no pasa nada si empiezan comiendo trocitos y luego se les ayuda aplicando alguna de las técnicas propuestas. Es de gran importancia, que los ingredientes que se utilicen para cocinar estos platos familiares sean naturales y sanos. Si se usan alimentos procesados, que sean los mínimos posibles y con buena calidad nutricional.

\section{Experimentar con los alimentos}

Significa que durante la comida o fuera de ella, se le ofrecen alimentos al niño para que vea que tienen distinto olor, color, forma, textura, consistencia y sabor. Los bebés los toman como si fuese un juguete nuevo que lo lamen (por lo que tiene que estar limpio y no ser un alimento de riesgo de intoxicación como el huevo), muerden (evitar alimentos potenciales de riesgo de asfixia o atragantamiento) y tiran al suelo para ver qué ruido hace, etc.; así se fomenta el aprendizaje de comer, aprenden a controlar su fuerza para no aplastar, a ponerse trozos de tamaño adecuado a su boca, etc.

\section{Experimentar con texturas y alimentos nuevos}

Los padres pueden ofrecerle alimentos modificando la temperatura (p.e.: granizado de sólo fruta congelada), o bien texturas como gelatinas suaves con base de frutas o leches, o bien texturas más cremosas (p.e.: natillas caseras con base de aguacate y plátano).

\section{ADVERTENCIAS Y PRECAUCIONES}

Pese a la falta de evidencia científica sobre qué método de beikost es el ideal, los padres deben decidir el método que quieren aplicar para iniciar el beikost. Se recomienda a los profesionales sanitarios que no les asesoren sobre un método en concreto, sin tener en cuenta todos los factores influyentes en los padres que aparecen en el estudio de Harrison et al. ${ }^{18}$, de esta forma se les puede asesorar de una forma más personalizada sobre las texturas que necesitan aplicar en función del método que escojan.

Por precaución, los padres deben vigilar aquellos alimentos que tienen más riesgo de aspiración y asfixia. En etapas más tempranas se debe excluir aquellos alimentos que puedan causar riesgo de atragantamiento, e informar a los padres de las técnicas de emergencias, como la maniobra de Heimblich para bebés, por si se encontrasen en la situación (aunque de una forma no alarmante). Así evitaremos todo aquello que tenga forma redondeada u ovalada, pequeña y dura que pueda obstruir las vías respiratorias, algunos ejemplos son: salchichas, manzana, zanahoria, hojas de lechuga o brotes y apio crudos, cerezas, uvas, bayas, tomates cherry sin partir por la mitad, guisantes, granada, maíz entero, frutos secos enteros o mal triturados, pasas, patatas fritas, palomitas (por sus pieles), biscotes, pan tostado, caramelos ${ }^{63}$, mini-gelatinas tipo golosina y otros alimentos que vengan en envases que se tengan que estrujar y succionar (p.e.: purés, yogures... y, si se dan, es mejor vaciar el contenido en una cuchara para evitar riesgo de asfixia por aspiración) $)^{59,64}$.

Hay que evitar alargar los purés, papillas o potitos más allá de los 10 meses. Ya que se considera una ventana crítica en la introducción de los alimentos. Si por comodidad de los padres, no se ofrecen alimentos sólidos a trocitos el lactante tendrá más problemas en aprender a comer de todo y de cualquier textura ${ }^{36,37}$.

Vigilar las texturas viscosas porque el bebé tarda más en deglutirlas $y$, aunque su composición nutricional sea adecuada, la ingesta puede ser insuficiente (un ejemplo serían los guisos de consistencia más líquida). Es importante ofrecer una viscosidad adecuada para que el bebé sea capaz de comer más cantidad ${ }^{37}$. Se les puede añadir algún tipo de espesante natural como maicena, kudzu, agar... o triturar parte de las verduras, tubérculos, cereales o legumbres para espesar dicho plato.

Pérez $P$. et al. indica cómo los bebés a término con factores de riesgo, podrían tener problemas motores que hayan pasado desapercibidos ${ }^{47}$.Por eso la introducción de nuevos alimentos y los cambios de texturas se deben aplicar con precaución.

De cara a los profesionales sanitarios, aconsejamos que se explique qué significa el destete. Concepto que se está usando para hablar de la introducción alimentaria y que crea confusión a los padres, que creen que significa abandonar la lactancia materna a partir de los 6 meses, cuando precisamente lo que se fomenta es que se alargue hasta los 2 años o más. 


\section{$\longrightarrow$ \\ PROPUESTA DE NUEVAS LÍNEAS DE INVESTIGACIÓN}

Tras la realización de esta revisión, proponemos las siguientes líneas de investigación, las cuales podrían aportar nueva información al debate actual sobre qué método y texturas de beikost son la mejor opción tanto para bebés nacidos a término y sanos como para prematuros, con problemas de desarrollo psicomotor o con problemas del aparato digestivo.

La primera sería investigar sobre la posibilidad de que el causante del sobrepeso que algunos estudios relacionan con el método tradicional, se deba a la ingesta de alimentos procesados diseñados para bebés y no debido a la textura triturada de sus purés.

La segunda línea podría ser, averiguar si el \% de atragantamientos que aparecen en los estudios en contra del BLW se deben realmente al atragantamiento o por el contrario, a alguno de los siguientes factores:

- Los padres no saben distinguir entre arcada o asfixia.

- Los bebés continúan comiendo cuando ríen, lloran, caminan o corren.

En tercer lugar, sería interesante estudiar qué ingredientes y qué combinaciones serían óptimas para diseñar platos con una textura determinada y con los macronutrientes y micronutrientes necesarios para evitar problemas de déficits nutricionales (hierro, vitamina D, B12, zinc) o de exceso de sodio, azúcar o grasa saturada. Y continuar la investigación sobre el beikost en prematuros y bebés con enfermedades que se relacionan a problemas psicomotores.

Y para finalizar, investigar sobre cómo aplicar el beikost en prematuros y bebés con enfermedades relacionadas con problemas psicomotores o fisiológicos debido a malformaciones o síndromes genéticos entre otros problemas ${ }^{46}$. Por un lado es muy recomendable la estimulación psicomotora temprana (antes de los 12 meses) en todos los bebés usando los alimentos limpios como juguete de experimentación y bajo vigilancia ${ }^{48}$ Pero por otro, en los diferentes estudios se ha visto cómo algunos bebés prematuros no tendrían problemas psicomotores por lo que podrían presentar las señales de estar preparados para comer, ya que son capaces de sentarse o aguantar la cabeza; pero al presentar problemas cognitivos, no serían capaces de aplicar texturas del BLW para alimentarse solos, ya que la manipulación fina no la tendrían completamente desarrollada ${ }^{45}$. Reimundo E.A. comenta que esta diferencia entre prematuros y bebés a término se evidencia sobre todo entre el segundo y quinto mes y que entre el noveno y onceavo la diferencia no es tan grande ${ }^{48}$. Esto podría ser una pista de que los prematuros a partir de los 7 meses y sobre todo a partir de los 9 meses, podrían estar preparados para una alimentación guiada por el bebé, ubicándose dentro de la ventana crítica para comer trocitos y no solamente purés. Pero esta investigación se tendría que hacer una vez se llegase a un consenso para aplicar el beikost en los bebés nacidos a término.

\section{$\longrightarrow$ CONCLUSIONES}

La introducción de alimentos es un gran paso en la evolución y autonomía del bebé, que se debe realizar sin prisas ni nervios. Existe gran variedad de edades para alcanzar los hitos motores relacionados con el acto de comer, perfectamente compatible con un normal desarrollo. Por lo que hay que alentar a los padres a que no tengan miedo a cocinar y combinar los alimentos para obtener texturas sanas, equilibradas y seguras para ofrecer a sus pequeños a partir del sexto mes. Y no hay que esperar que todos los bebés estén preparados en la misma fecha y el modo de saberlo será probando y observando con mucha cautela y sentido común. El beikost hasta el año de vida debe complementar a la lactancia materna y no al revés. A partir de este momento los alimentos comenzarán a tomar más importancia, pero la lactancia seguirá hasta los 2 años de edad o hasta producirse un destete paulatino debido a una decisión del bebé o de la madre. De esta forma se ayuda a conseguir los objetivos para la OMS 2025. Para que la aceptación de las nuevas texturas sea buena, es posible que sea importante que estén adaptadas a la capacidad de masticación del niño, así como exponer tempranamente y permitirle que manipule dichas texturas. Probablemente la introducción de la alimentación complementaria deba ser lenta, progresiva y coherente con la erupción de los dientes y la capacidad para masticar. El cambio progresivo de textura, aun cuando no hayan salido los dientes, fomenta el endurecimiento de las encías y el desarrollo de la cavidad oral. Estimular el desarrollo de una masticación eficiente y completa durante los primeros años de vida, seguramente aporte muchos beneficios tanto en el momento actual como en la edad adulta, influya en el proceso de saciedad y mejore la absorción de nutrientes. Para desarrollar el crecimiento óptimo del niño, es recomendable aumentar gradualmente la consistencia de los alimentos, incluso cuando esto requiera más tiempo por parte de los cuidadores. Sin olvidar que la presentación de los alimentos en trocitos o con grumos debería producirse antes de la ventana de edad crítica de 10 meses para evitar el riesgo latente de dificultad alimentaria asociada con 
la introducción tardía. Se requieren más y mejores estudios para evaluar de forma empírica el impacto de las diferentes texturas y métodos de alimentación.

\section{$\longrightarrow$ CONFLICTO DE INTERESES}

Los autores son miembros del Grupo de Especialización en Nutrición Pediátrica de la Academia Española de Nutición y Dietética. La Revista Española de Nutrición Humana y Dietética es la revista científica de la Academia Española de Nutrición y Dietética.

\section{7 ? \\ REFERENCIAS}

(1) ESPGHAN Committee on Nutrition. Complementary Feeding: A Commentary by the ESPGHAN Committee on Nutrition. Journal of Pediatric Gastroenterology and Nutrition, 2008. [Consultado 25-07-2018]. Disponible en: 46:99-110 https:// www.ncbi.nIm.nih.gov/pubmed/18162844

(2) Prell C, Koletzko B: Breastfeeding and complementary feeding-recommendations on infant nutrition. Dtsch Arztebl Int 2016; 113: 435-44. [Consultado 25-07-2018] Disponible en: https://www.aerzteblatt.de/int/archive/ article/180189/Breastfeeding-and-complementary-feedingrecommendations-on-infant-nutrition

(3) Fewtrell M, Bronsky J, Campoy C, Domellöf M, Embleton N, Fidler Mis N, Hojsak I, Hulst JM, Indrio F, Lapillonne A, Molgaard C. Complementary Feeding: A Position Paper by the European Society for Paediatric Gastroenterology, Hepatology, and Nutrition (ESPGHAN) Committee on Nutrition. ] Pediatr Gastroenterol Nutr. 2017; 64(4): 653. [Consultado el 01/02/2019]. Disponible en: https://journals.Iww.com/ ipgn/Fulltext/2017/01000/Complementary_Feeding____ Position Paper by the.21.aspx

(4) World Health Organization. The optimal duration of exclusive breastfeeding: re- port of an expert consultation. [Consultado 2507-2018]. Disponible en: hwww.who.int/nutrition/publications/ optimal_duration_of_exc_bfeeding_report_eng.pdf

(5) PEN: practice-base $\bar{d}$ evidence in nutrition.Infant Nutrition - Breastfeeding [Internet]. 2017 [Consultado 26 de julio de 2018]. Disponible en: http://www.pennutrition.com/ KnowledgePathway.aspx?kpid $=2018 \&$ tkid $=20314$

(6) Brown A, Jones SW, Rowan H. Baby-Led Weaning: The Evidence to Date. Curr Nutr Rep. 2017; 6(2): 148-156. [Consultado el 10/01/2019]. Disponible en: https://www.ncbi.nlm.nih.gov/ pubmed/28596930

(7) OMS. La alimentación del lactante y del niño pequeño. Alimentación complementaria. [Internet] OMS; 2009. [Consultado 16 febrero 2009]. Disponible en: http://new.paho. $\mathrm{org} / \mathrm{hq} / \mathrm{dmdocuments} / 2010 /$ La-alimentacion-del-lactante-capitulo-modelo-para-libros-de-texto.pdf
(8) Organización Mundial de la Salud (OMS). Alimentación del lactante y del niño pequeño. [Internet] 2010. [Consultado 1012-2016]. Disponible en: http://www.slan.org.ve/libros/Laalimentaci\%C3\%B3n-del-lactante-y-del-nino-pequeno.pdf

(9) OMS. Metas mundiales de nutrición 2025: Serie de documentos normativos [Internet]. WHO. [consultado 25 de julio de 2018]. Disponible en: http://www.who.int/nutrition/publications/ globaltargets2025_policybrief_overview/es/

(10) Rogers SL, Blissett J. Breastfeeding duration and its relation to weight gain, eating behaviours and positive maternal feeding practices in infancy. Appetite. 2017; 108: 399-406. [Consultado 24-07-2018]. Disponible en: https://www.ncbi.nlm.nih.gov/ pubmed/27756634

(11) Daniels L, Heath A-LM, Williams SM, Cameron SL, Fleming EA, Taylor B], et al. Baby-Led Introduction to SolidS (BLISS) study: a randomised controlled trial of a baby-led approach to complementary feeding. BMC Pediatr. 12 de noviembre de 2015; 15: 179. [Consultado 27-07-2018]. Disponible en: https://www.ncbi.nlm.nih.gov/pubmed/26563757

(12) D'Andrea E, Jenkins K, Mathews M, Roebothan B. Baby-led Weaning: A Preliminary Investigation. Can J Diet Pract Res. 2016; 77(2): 72-7. [Consultado 27-07-2018]. Disponible en: https://www.ncbi.nlm.nih.gov/pubmed/26771760

(13) Arden MA, Abbott RL. Experiences of baby-led weaning: trust, control and renegotiation. Matern Child Nutr. 2015; 11(4): 82944. [Consultado 25-07-2018]. Disponible en: https://www. ncbi.nlm.nih.gov/pubmed/27154478

(14) Morison BJ, Taylor RW, Haszard JJ, Schramm CJ, Williams Erickson L, Fangupo L], et al. How different are baby-led weaning and conventional complementary feeding? A crosssectional study of infants aged 6-8 months. BM] Open. 2016; 6(5): e010665. [Consultado 26-07-2018]. Disponible en: https://www.ncbi.nlm.nih.gov/pubmed/27154478

(15) PEN: practice-based evidence in nutrition. Do infants aged six to 12 months who are introduced to solids using the babyled weaning (BLW) technique (i.e. infants self-fed with finger food) compared to infants who are introduced to solids using the traditional spoon-fed (TSF) method (with gradual texture progression) have any differences in growth and/ or developmental patterns? [Internet]. 2018 [consultado 25 de julio de 2018]. Disponible en: http://www.pennutrition. com/KnowledgePathway. aspx?kpid=2503\& pqcatid $=146 \&$ pq id $=2035$

(16) Cameron SL, Heath A-LM, Taylor RW. How feasible is Baby-led Weaning as an approach to infant feeding? A review of the evidence. Nutrients. 2012; 4(11): 1575-609. [Consultado 2507-2018].

(17) D'Auria E, Bergamini M, Staiano A, Banderali G, Pendezza E, Penagini F, Zuccotti GV, Peroni DG; Italian Society of Pediatrics. Baby-led weaning: what a systematic review of the literature adds on. Ital ] Pediatr. 2018; 44(1): 49 [Consultado el 15/01/2019]. Disponible en: https://www.ncbi.nlm.nih.gov/ pubmed/29724233

(18) Harrison M, Brodribb W, Hepworth J. A qualitative systematic review of maternal infant feeding practices in transitioning from milk feeds to family foods. Matern Child Nutr. 2017; 13(2). doi: 10.1111/mcn.12360. Epub. 2016 Oct 3. [Consultado el 19/01/2019]. Disponible en: https://www.ncbi.nlm.nih.gov/ pubmed/27696658 
(19) Macías S, Rodríguez S, Ronayne de Ferrer P. Leche materna: composición y factores condicionantes de la lactancia. Arch Argent Pediatr. 2006; 104(5): 423-30.

(20) Rojas C, Guerrero R. Nutrición clínica y gastroenterología pediátrica. Bogotá-Colombia. Ed. Panamericana; 1999. p.26.

(21) Gil A. Tratado de nutrición. Nutrición humana en el estado de salud. 2a ed. Vol. 3 Editorial Médica Panamericana, S.A.; 2010. p. 208-211.

(22) Noguera R. Manual de Pediatría. Costa Rica: 2009.

(23) Leal de la Rosa J, Marta García M. Patología digestiva y muerte súbita del lactante. En: Izquierdo I/ AEPED. Libro blanco de la muerte súbita infantil. 3a ed. Madrid. Ediciones Ergon; 2013. p. 171-79.

(24) Gorostidi M, Santamaría R, Alcázar R, Fernández-Fresnedo G, M. Galcerán J, Marián Goicoechea M, et al. Documento de la Sociedad Española de Nefrología sobre las guías KDIGO para la evaluación y el tratamiento de la enfermedad renal crónica. Nefrologia. 2014; 34(3): 302-16.

(25) Posada A, Gómez JF, Ramírez H. El niño sano. Editorial Médica Panamericana, S.A.; 2006. p. 274.

(26) Carmuega E. Aspectos fisiológicos de la alimentación en el primer año de vida. [Internet] Buenos Aires: Universidad de Buenos Aires. [Consultado 25-01-2017]. Disponible en: http://www.fmed.uba.ar/depto/alim_n_sano/Boletin_CESNI_ fisiologia_lactante\%5B1\%5D.pdf

(27) Moro M, Málaga S, Madero L. Cruz. Tratado de Pediatría. 11a ed. 2014. Madrid: AEP. Editorial Médica Panamericana, S.A.; 2014.

(28) Cilleruelo ML, Fernández S. Protocolos diagnósticoterapéuticos de Gastroenterología, Hepatología y Nutrición Pediátrica SEGHNP-AEP. [Internet]. 2a ed. Madrid. Ediciones Ergon; 2010. p. 85-96 Disponible en: https://www.aeped.es/ sites/default/files/documentos/gastritis.pdf

(29) Clínica Dam [internet]. Madrid: 12 enero 2017 [Consultado 16 febrero 2017]. Disponible en: https://www.clinicadam.com/ salud/5/001155.htm

(30) Infant \& toddler forum. Developmental stages in infant and toddler feeding. Feeding young children: practical advice from experts. [Internet] 2014 [Consultado 24-01-2017]. Disponible en: http://www.infantandtoddlerforum.org

(31) González C, Carmen Frontela C, Peso P, López R, Martínez C. Empleo de fórmulas infantiles antiregurgitación en lactantes. Efecto sobre la disposición del mineral. Rev Chil Nutr. 2011; 4(38): 482-90.

(32) Montenegro R, Guerrero L. Nutrición Clínica y Gastroenterología Pediátrica. Bogotá: Editorial Médica Panamericana; 1999. p. 24-25.

(33) Martín Moreno V, Molina Cabrerizo MR, Gómez Gómez C. Duración de la lactancia materna, erupción de los primeros dientes temporales y desarrollo antropométrico alcanzado a los dos años de vida. Nutr Hosp. 2006; 21(3): 362-8. Disponible en: http://scielo.isciii.es/scielo.php?script=sci_arttext\&pid =S0212-16112006000300012

(34) Torres M. Desarrollo de la dentición. La dentición primaria. Ortodoncia.ws [Internet] 2009. [Consultado 12 enero 2017]; Disponible en: https://www.ortodoncia.ws/ publicaciones/2009/art23.asp

(35) Briolotti, A. Desarrollo psicológico, naturaleza y cultura en la teoría de Arnold Gesell: un análisis de la psicología como disciplina de saber-poder. (págs. 55-70). 2015. Brasil: Memorandum: Memória e História em Psicología.
(36) Abeshu MA, Lelisa A, Geleta B. Complementary Feeding: Review of Recommendations, Feeding Practices, and Adequacy of Homemade Complementary Food Preparations in Developing Countries - Lessons from ethiopia. [Internet]. Frontiers in Nutrition. 2016; 3: 41 [Consultado 15-12-2016]. Disponible en: https://www.ncbi.nlm.nih.gov/pubmed/27800479

(37) Setton D, Fernández A. Alimentación complementaria en los dos primeros años de vida. En: Piazza N. Nutrición Pediátrica. Ciudad Autónoma de Buenos Aires: Ed. Panamericana; 2014. p. 135-140.

(38) Dodds R. Baby-led weaning is associated with less parental control of children's eating and lower Body Mass Index Perspective [Internet]. London: $\mathrm{NCT}^{\prime}$ s; March 2013. [Consultado 12 febrero 2017]. Disponible en: https://www.nct.org.uk/ sites/default/files/related_documents/Dodds\%20Babyled $\% 20$ weaning $\% 20$ is $\% 20$ associated $\% 20$ with $\% 20$ less $\% 20$ parental\%20control\%20 of $\% 20$ children ${ }^{1}$ s $\% 20$ eating $\% 20$ and\%20lower\%20BMI\%20p14-15\%20Mar13.pdf

(39) PEN: practice-based evidence in nutrition. Do infants aged six to 12 months who are introduced to solids using the babyled weaning $(B L W)$ technique (i.e. infants self-fed with finger food) compared to infants who are introduced to solids using the traditional spoon-fed (TSF) method (with gradual texture progression) have any differences in growth and/or developmental patterns? [Internet]. mayo 2018 [Consultado 25 de julio de 2018]. Disponible en: http://www.pennutrition. com/KnowledgePathway.aspx?kpid=2503\&pqcatid $=146 \&$ pq id $=20235$

(40) PEN: practice-based evidence in nutrition. What are the characteristics and beliefs of mothers and health care professionals regarding the baby-led weaning (BLW) approach? [Internet]. 2018 [Consultado 27 de julio de 2018]. Disponible en: http://www.pennutrition.com/KnowledgePathway.aspx?k pid $=2503 \&$ pqcatid $=145 \&$ pqid $=26574$

(41) Carruth BR, Ziegler PJ, Gordon A, Hendricks K. Developmental milestones and self-feeding behaviors in infants and toddlers. ] Am Diet Assoc. 2004; 104(1 Suppl 1): S51-6. [Internet] [Consultado 13-02-2017] Disponible en: https://www.ncbi. nlm.nih.gov/pubmed/14702018

(42) Berger. Los primeros dos años: el desarrollo biosocial. Psicología del desarrollo. 9a ed. Estados Unidos: Panamericana; 2012.

(43) M. Bueno, A. Sarriá, J.M. Pérez-González. Alimentación Complementaria. En: Bueno O, Bueno-Lozano M. Nutrición en pediatría. 3a ed. Madrid: Ediciones Ergon; 2007. p. 173-178.

(44) Pérez G. Psicopedagogía Desarrollo del Bebé: 0-20 meses [Internet]. [consultado 4 de julio de 2018]. Disponible en: https://www.psicopedagogia.com/articulos/?articulo=313

(45) Pinello L, Manea S, Visonà Dalla Pozza L, Mazzarolo M, Facchin P. Visual, motor, and psychomotor development in small-forgestational-age preterm infants. J AAPOS Off Publ Am Assoc Pediatr Ophthalmol Strabismus. 2013; 17(4): 352-6.

(46) Eickmann SH, Malkes NF de A, Lima M de C. Psychomotor development of preterm infants aged 6 to 12 months. Sao Paulo Med J. 2012; 130(5): 299-306.

(47) Perez-Pereira M, Fernandez P, Gómez-Taibo M, Gonzalez L, Trisac JL, Casares J, et al. Neurobehavioral development of preterm and full term children: biomedical and environmental influences. Early Hum Dev. 2013 ;89(6): 401-9.

(48) Reimundo EA. Perfil del desarrollo psicomotor de niños y niñas 
menores de 12 meses de edad nacidos a pretérmino. [Proyecto de investigación] Quito. Universidad central del Ecuador; 2018.

(49) Cristancho LR, et al. Prevalencia del riesgo de alteraciones en el desarrollo neuroconductual en una población de lactantes de México en 2012. Revista Española de Discapacidad. 2018; 6(I): 241-55. [Consultado 26-07-2018].

(50) Fangupo L], Heath A-LM, Williams SM, Erickson Williams LW, Morison BJ, Fleming EA, et al. A Baby-Led Approach to Eating Solids and Risk of Choking. Pediatrics. 2016; 138(4). [Consultado 27-07-2018]. Disponible en: https://www.ncbi. nlm.nih.gov/pubmed/27647715

(51) Williams L, Taylor R, Haszard J, Fleming E, Daniels L, Morison $B$, et al. Impact of a Modified Version of Baby-Led Weaning on Infant Food and Nutrient Intakes: The BLISS Randomized Controlled Trial. Nutrients. 2018; 10(6) [Consultado 24-072018]. Disponible en: https://www.ncbi.nlm.nih.gov/pmc/ articles/PMC6024590/

(52) Espín Jaime B, Martínez Rubio A. El paso de la teta a la mesa sin guión escrito. Baby led weaning: ¿ventajas?, ¿riesgos? En: AEPap (ed.). Curso de Actualización Pediatría 2016. Madrid: Lúa Ediciones 3.0; 2016. p. 59-66.

(53) Red Europea para la Nutrición Pública Saludable: Trabajo en red, Monitorización, Intervención y Formación (EUNUTNET). Alimentación de los lactantes y niños pequeños: Normas recomendadas para la Unión Europea. [Internet] 2005-2006. [Consultado 10-11-2016]. Disponible en: http://www.aeped. es/sites/default/files/2-alimentacionlactantes_normas_ recomendadasue.pdf

(54) Organización Mundial de la Salud (OMS). Guiding principles for feeding non-breastfed 6 - 24 months of age. [Internet] 2005. [Consultado 15-12-2016]. Disponible en: http://www.who.int/ nutrition/publications/guidingprin_nonbreastfed_child.pdf

(55) Organización de las Naciones Unidas para la Agricultura y la Alimentación (FAO). Guía de la nutrición en familia. [Internet] 2006. [Consultado 10-12-2016]. Disponible en: http://www. fao.org/3/y5740s/y5740s.pdf

(56) Best start meilleur départ. Feeding your baby. From six months to one year. [Internet] 2015 [Consultado 13-022017] Disponible en: https://www.beststart.org/resources/ nutrition/pdf/BSRC_FeedingYourBaby_2015.pdf
(57) Fondo de Naciones Unidas para la Infancia (UNICEF). Los primeros olores de mi cocina. [Internet] 2008. [Consultado 10-12-2016]. Disponible en: https://www.unicef.org/uruguay/ spanish/los_primeros_olores.pdf

(58) Daniels L, Heath AM, Williams SM, Cameron S, Fleming EA, Taylor BJ, et al. Baby-Led Introduction to SolidS (BLISS) study: a randomised controlled trial of a baby-led approach to complementary feeding. [Internet]. [Consultado 13-02-2017]. BMC Pediatr. 2015; 15: 179. Disponible en: https://www.ncbi. nIm.nih.gov/pmc/articles/PMC4643507/

(59) Le Révérend BJ, Edelson LR, Loret C. Anatomical, functional, physiological and behavioural aspects of the development of mastication in early childhood. [Internet] [Consultado 13-012017] British Journal of Nutrition. 2014;111:403-14. Disponible en: https://www.ncbi.nIm.nih.gov/pubmed/24063732

(60) Cochrane Database of Systematic Reviews. Optimal duration of exclusive breastfeeding. [Consultado el 27/01/2019] Disponible en: https://www.cochranelibrary.com/cdsr/ doi/10.1002/14651858.CD003517.pub2/full

(61) Larsson E. Orthodontic aspects on feeding of young children: 1. A comparison between Swedish and Norwegian-Sami children. Swed Dent J. 1998; 22: 117-21.

(62) Cameron SL, Heath AM, Taylor RW. How Feasible Is Baby-Led Weaning as an Approach to Infant Feeding? A Review of the Evidence [Internet] [Consultado 13-02-2017]. Nutrients. 2012; 4(11): 1575-1609. Disponible en: http://www.mdpi.com/2072$6643 / 4 / 11 / 1575$

(63) Cameron SL, Taylor RW, Heath AM. Development and pilot testing of baby-led introduction to solids - a version of baby-led weaning modified to address concerns about iron deficiency, growth faltering and choking. [Internet]. [Consultado 1302-2017]. BMC Pediatr. 2015; 15: 99. Disponible en: http:// bmcpediatr.biomedcentral.com/articles/10.1186/s12887015-0422-8

(64) Instituto Nacional de Vigencia de Medicamentos y Alimentos (INVIMA). Resolución 79980 de 2015. [Internet] 09-102015 [Consultado 13-02-2017]. Disponible en: https:// normativa.colpensiones.gov.co/colpens/docs/pdf/resolucion_ superindustria_79980_2015.pdf 